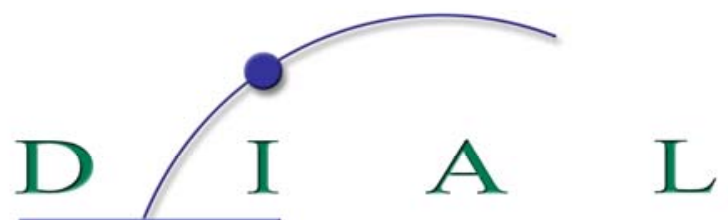

Développement Institutions \& Analyses de Long terme

DOCUMENT DE TRAVAIL

DT/2009-01

\title{
More Jobs for University \\ Graduates: Some Policy Options for Tunisia
}

Mohamed Ali MAROUANI

DIAL・ 4, rue d’Enghien • 75010 Paris • Téléphone (33) 0153241450 • Fax (33) 0153241451 E-mail : dial@dial.prd.fr • Site : www.dial.prd.fr

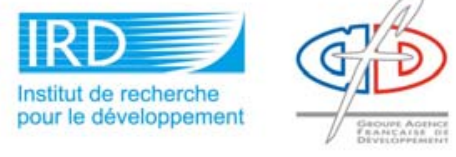




\title{
MORE JOBS FOR UNIVERSITY GRADUATES: SOME POLICY OPTIONS FOR TUNISIA ${ }^{1}$
}

\author{
Mohamed Ali Marouani \\ Université Paris1-Panthéon-Sorbonne \\ IEDES, DIAL et ERF \\ marouani@univ-paris1.fr
}

Document de travail DIAL

Février 2009

\begin{abstract}
The combination of demographic factors and an increase in education has caused a significant rise of university graduates' unemployment in the MENA region. The article provides a prospective costeffectiveness analysis of the impact of alternative labor market policies using a dynamic general equilibrium model. The model allows for an endogenous determination of unemployment through a multisectoral efficiency wage setting mechanism. The main finding is that a wage subsidy targeted at highly skilled intensive sectors is more effective than tax reductions or investment subsidies. However, wage subsidies are not enough to reduce significantly unemployment. Other policy options need to be considered.
\end{abstract}

Keywords: Employment policies, skilled workers, unemployment, dynamic general equilibrium models, Middle East and North Africa, Tunisia.

\section{RESUME}

La combinaison de facteurs démographiques et de progrès dans l'éducation a entraîné une hausse significative du chômage des diplômés dans la région MENA. L'article fournit une analyse de type coût-efficacité de politiques alternatives d'mploi à l'aide d'un modèle d'équilibre général dynamique. Le modèle permet une détermination endogène du niveau de chômage à l'aide d'un modèle multisectoriel de salaires d'efficience. Le principal résultat est qu'une subvention salariale ciblée sur les secteurs intensifs en main-d'œuvre qualifiée est plus efficace que des réductions d'impôts ou des subventions à l'investissement. Cependant ces subventions salariales ne sont pas suffisantes pour réduire significativement le niveau du chômage. D’autres options doivent être considérées.

Mots clés : politiques de l'emploi, main-d'oeuvre qualifiée, chômage, modèle d'équilibre general dynamiques, Afrique du Nord et Moyen Orient, Tunisie..

JEL Code: C68, J24, J68 


\section{Contents}

1 INTRODUCTION

2 A DYNAMIC GENERAL EQUILIBRIUM FRAMEWORK .................................................. 4

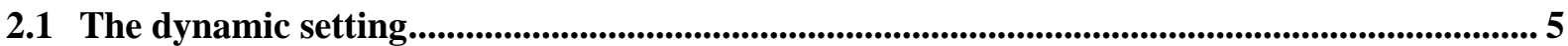

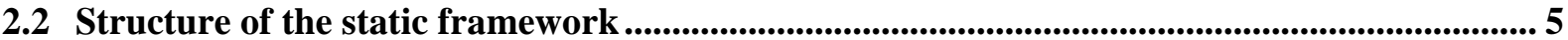

2.2.1 The production and factor demand block ........................................................................... 5

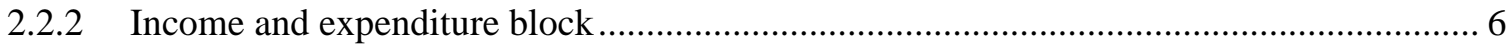

2.2.3 The equilibrium conditions and macroeconomic closure ................................................ 6

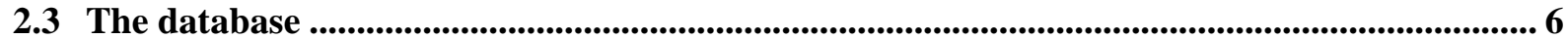

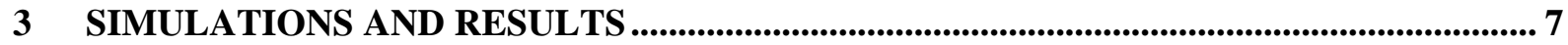

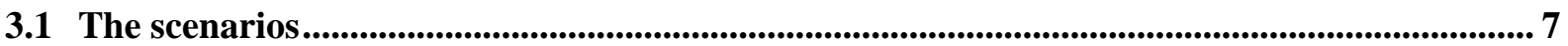

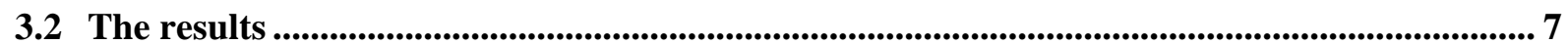

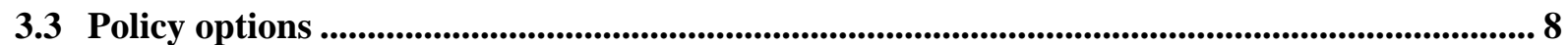

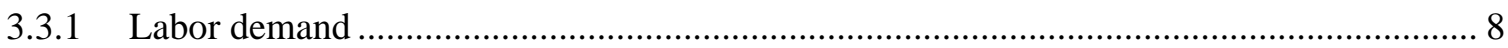

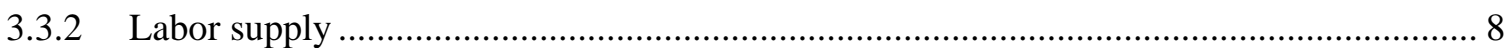

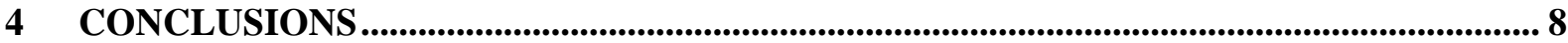

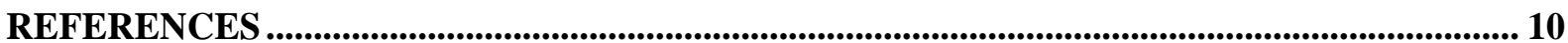

\section{List of tables}

Table 1: Evolution of the main variables of interest by 2012 (comparison with the reference scenario) 7 


\section{INTRODUCTION}

As in many MENA countries the persistence of high unemployment rates, especially among the youth, has been the major concern for policymakers in Tunisia in the last decade. The increase in the supply of educated workers will induce a significant shift in the skill composition of the labor force. According to the World Bank (2004) the supply of highly educated workers will increase by about $9 \%$ per year in the next decade, which puts a heavy pressure on the creation of skilled jobs.

The improvement of the level of education of the labor force is a chance for Tunisia because it could contribute to a shift of the structure of the economy towards higher value-added activities in the long run. However if the new cohorts of educated workers find themselves unemployed, households could be less motivated in investing in human capital. Moreover, the society pays a high cost for every young person reaching a university degree. It is thus a waste of public resources to leave a significant share of the stock of human capital unemployed. Finally, given that education is the best way to achieve social mobility, higher unemployment within the highly skilled will disfavor relatively more the less wealthy who can not rely on physical capital assets to create their own businesses, nor on social capital to get the good jobs due to the rationing that will inevitably grow in the market of skilled labor.

Implementing active labor market policies targeted at this category of workers seems thus a necessity. The question that remains is what kind of policies are the most effective. Ex ante and ex post assessments are thus needed to avoid the waste of public funds. The objective of the research presented in this article is to simulate alternative labor market policies to quantify their effects on skilled unemployment and their costs for the Government budget in the medium run (the next five years).

Given the issue at stake a dynamic multisectoral general equilibrium model seems a well suited tool since it permits to deal with the direct and indirect effects of a shock on the different components of the economy. In addition, disaggregating the economy into industries allows for targeting some shocks on specific sectors.

Since we focus on the effects of the labor market policies on unemployment, a significant part of the modeling effort is devoted to the labor market. Thus, intersectoral wage differentials are endogenously determined, and explained by efficiency considerations. We propose a multisectoral model of efficiency wages based on imperfect monitoring considerations. This model is developed in detail in Marouani (2000), and follows the work of Shapiro and Stiglitz (1984) and Walsh (1999). Two sectors receive a different treatment: the Government sector, where wages are set by the Government, and the agricultural sector where the rural / urban migration process is modeled through an extended Harris / Todaro function.

The paper is organized as follows: section two presents the general equilibrium model and the database, section three presents the simulations, the results and some policy options and section four concludes.

\section{A DYNAMIC GENERAL EQUILIBRIUM FRAMEWORK}

In presenting the model we will first describe its dynamic dimension, which is intended to capture the evolution of jumping variables (capital, labor force, productivity, etc.), and then the intra-period dimension, which is equivalent to a one-year static CGE model. 


\subsection{The dynamic setting}

The main features of the dynamic setting are described hereafter:

Capital accumulation is sectoral. Each year the stock of capital of each sector corresponds to the sum of the stock of last year and new investment minus the depreciation of capital. Following Bchir et al. (2002), sectoral investment (INVi) has been modeled as a function of the sectoral stocks of capital $(K D i)$, sectoral rates of return to capital (rki) and capital acquisition costs $(P K)$ :

$$
I N V_{i}=\operatorname{gamma}_{i} * K D_{i} * e^{\frac{\text { lambda* }^{*} k_{i}}{P K-s u b v_{i}}}
$$

Where gamma is a scale parameter (calibrated), lambda is the elasticity of investment to the rate of return to capital and subvi are sectoral subsidies to investment.

Labor force growth is differentiated by skills and varies according to exogenous rates estimated by the World Bank (2004). Total productivity grows according to an exogenous rate determined through the dynamic calibration process.

Public spending and civil servants' wages grow also according to exogenous rates fixed by the government. The evolution of exchange rate has been set so as to reflect the actual management of the exchange rate in Tunisia. Finally transfers between the different agents (households, government, firms and rest of the world) grow at the same rate as GDP.

\subsection{Structure of the static framework}

The Tunisian economy is disaggregated into twenty sectors. The model distinguishes four inputs: three categories of labor and capital, and four types of agents: a representative household, firms, the government and the rest of the world. We develop only the blocks that are relevant for the current article.

\subsubsection{The production and factor demand block}

The production function is a nested one which permits to capture the substitution and complement relations among the various inputs. Value added (VA) is a nested Constant Elasticity of Substitution (CES) function. VA is a CES of two composite bundles: the first bundle is a CES function of unskilled and skilled labor whereas the second bundle is a CES of capital and highly skilled labor, which are supposed to be highly complementary. Concerning the Government sector, capital and the three labor categories are set in fixed proportions.

The three categories of workers are supposed to be mobile across sectors, but workers are not allowed to look for a job requiring more or less qualifications than they have. In the urban private sector, wages and unemployment are determined through a multisectoral efficiency wages setting mechanism (Marouani, 2000).

$$
w_{\text {if }}^{*}=\left(1+\frac{b_{i f}+r}{q_{i f}}\right) e_{i f}+\sum_{j=1}^{n} \frac{b_{j f}{ }^{L} j f}{j f} e_{f} j f
$$

where $r$ is the discount rate, $i$ the sector, $f$ the level of qualification, $w$ is the wage, $e$ is the disutility of effort, $b$ is the exogenous separation rate, $q$ is the probability of being caught shirking and, $L$ is labor demand by sector and skill and $U$ the unemployment rate by skill. 
The advantage of such a specification is that it permits to avoid modeling wages as completely flexible or completely fixed ${ }^{2}$.

In the agricultural sector the wage is linked to the average urban wage through an extended HarrisTodaro function ${ }^{3}$ capturing the difficulty of getting an urban job for a rural worker. Concerning civil servants, we suppose that the government sets their wages as a fixed proportion of the urban average wage. Physical capital is sector-specific in the short run.

\subsubsection{Income and expenditure block}

Households earn their income from wages, returns to capital, and transfers. Their expenditures are composed of interest payments and of consumption of goods and services. The Government earns income from various taxes (income taxes, corporate taxes, tariffs, production taxes and value added taxes) and from transfers. Its expenditures consist in Government consumption (mainly civil servants wages), transfers and public investment. The Government closure chosen is to allow public spending to grow at the GDP growth rate. Taxes are endogenized to ensure the stability of the ratio of public deficit to GDP.

\subsubsection{The equilibrium conditions and macroeconomic closure}

As previously established, the labor market is cleared through a joint determination of (efficiency) wages and the level of unemployment. By Walras' Law, commodities and labor market clearing, plus the restriction on Government budget (defined above) also imply equilibrium on the capital market.

The model is investment driven which means that households' savings (or debt) increase to ensure the equality between saving and investment.

\subsection{The database}

The model is calibrated from a 2001 database for the Tunisian economy. The advantage of using 2001 data is to be able to perform a dynamic calibration of the model by comparing the path of evolution of the main variables produced by the model with the actual path observed in the national accounts (2001-2005). The social accounting matrix (SAM) has been built on the basis of the Input-Output table provided by the Tunisian National Institute of Statistics. Aggregate investment by sector is provided in the national accounts (on the INS website). The data on employment and labor supply are from the population and employment census.

Calibration of the model involves selecting certain parameters from external sources (from the literature or fixed a priori) and deriving the remainder from identifying restrictions.

The interest rates are those practiced by the Tunisian Central Bank.

The disutility of effort parameter of the efficiency wages function is calibrated using the base year values of wages, employment, unemployment, the turnover rate and the probability of being detected shirking. The elasticity of mobility of rural workers in the Harris-Todaro function is calibrated from the benchmark data on agricultural and urban (average) wages, on employment in agricultural and non agricultural sectors, and on urban unemployment.

See for example Llop and Manresa (2004) who examine both cases for each simulation, which allows them in reality to analyze the extreme results of the interval, whereas our specification captures a continuous link between wages and unemployment.

The extension in The Harris-Todaro function consists in adding an elasticity of mobility for rural workers, calibrated from the base year values. 
The reference scenario includes the implementation of the gradual free trade agreement with the EU by $2008^{4}$ and the dismantling of the Multifiber Agreement in $2005^{5}$. The latter is modeled through an annual decrease of the export demand for Tunisian apparel products by $5 \%$ per year ${ }^{6}$.

\subsection{The scenarios}

Four scenarios are modeled. The first one consists in removing social security contributions on highly skilled workers (hsw). The second consists in providing a wage subsidy to activities that are the most intensive in hsw (the subsidy is equivalent to half the wage). The third consists in subsidizing investment in the most intensive sectors in hsw (subsidy of $20 \%$ of the investment cost). Finally the fourth simulation consists in removing the production tax on the most intensive sectors in highly skilled labor. The increase in public spending is financed through a uniform increase of all taxes except tariffs.

\subsection{The results}

Table 1: Evolution of the main variables of interest by 2012 (comparison with the reference scenario)

\begin{tabular}{|l||c|c|c|c||}
\hline \hline & $\begin{array}{c}\text { Scenario 1 } \\
\text { (removing social } \\
\text { security } \\
\text { contributions) }\end{array}$ & $\begin{array}{c}\text { Scenario 2 } \\
\text { (wage subsidies to } \\
\text { hsw) }\end{array}$ & $\begin{array}{c}\text { Scenario 3 } \\
\text { (investment } \\
\text { subsidies) }\end{array}$ & $\begin{array}{c}\text { Scenario 4 } \\
\text { (production tax } \\
\text { incentives) }\end{array}$ \\
\hline Total unemployment & -0.3 percentage point & -1.2 & -0.09 & -0.27 \\
\hline $\begin{array}{l}\text { Highly skilled labor } \\
\text { unemployment }\end{array}$ & -1.7 percentage point & -6.9 & -0.3 & -0.6 \\
\hline Taxes & $+7.5 \%$ & $+18.8 \%$ & $+21.2 \%$ & $+16.4 \%$ \\
\hline Investment & $+1.7 \%$ & $+4.8 \%$ & $+6.7 \%$ & $+3.2 \%$ \\
\hline
\end{tabular}

The simulations show clearly that the most efficient way of fighting highly skilled unemployment is to grant wage subsidies to this category of workers. However, despite its effectiveness this measure is not sufficient to reduce significantly highly skilled unemployment. Indeed, due to the high growth rate of highly skilled labor supply and to the relative rigidity of wages due to the efficiency wage hypothesis, the unemployment rate of this category of workers reaches 39\% in the reference scenario in 2012. This means that in the most optimistic scenario, highly educated workers' unemployment would reach $32 \%$ (scenario 2).

The first conclusion one can draw from this ex ante assessment is that tax incentives or subsidies for educated labor demand hiring will not be sufficient to solve the problem. Policymakers have thus to think about additional measures. The Tunisian employment strategy for the young educated workers has so far focused on two main axes: wage subsidies for a limited time-frame (the SIVP program) and micro-credit granted by the Banque Tunisienne de Solidarité. The first axis seems efficient according to our quantitative assessment, while we cannot assess the second due to the absence of a financial module in our model. These programs need to be assessed ex ante and ex post to help policymakers choose which one to strengthen the most. However, other measures would need to be implemented to reduce unemployment of highly skilled workers during the transition period where labor supply of educated will continue to increase at such a high level.

We can distinguish two kinds of policy options that could be implemented: measures which enhance labor demand and measures which reduce labor supply.

Excluding agricultural products and services.

See Marouani (2009) for an assessment of the impact of these shocks.

Rate observed in 2005 after the MFA phase out (World Bank, 2006). 


\subsection{Policy options}

\subsubsection{Labor demand}

A first potentially promising option is a massive increase in public research-development and incentives for enhancing private research-development. This measure could have a double dividend: increasing the demand for highly educated workers (engineers, researchers, etc.) in the short run and increasing productivity in the medium-long run which means higher growth and lower highly skilled labor costs and thus higher demand for highly educated workers in the medium long run. The difficulty of an ex ante assessment of such a measure resides in our poor knowledge of its costeffectiveness. In other words we need to investigate the effects on total productivity of a marginal Dinar spent on research-development. Introducing an ad hoc assumption of an increase in productivity in the CGE model without evaluating its corresponding cost is totally irrelevant.

The second option is to invest heavily in the promotion of highly skilled labor intensive services exports. The recent increase of the exports of medical services in Tunisia is a good example of the high potential of the country. The Government could also promote the development of exports of private education services (mainly for Arab and African students), software design, etc. An active trade policy could enhance the export of such kind of services. In its bilateral, regional and multilateral negotiations on services liberalization Tunisia should focus on mode 4 trade liberalization which allows the temporary movement of labor and which could favor the increase of highly skilled labor demand in Tunisia.

\subsubsection{Labor supply}

The most well-known way of reducing educated workers labor supply is to keep them studying as long as possible. The recent upsurge of technical degrees of shorter duration than usual university degrees (usually two years and a half) is thus questionable if we take into account the short-medium term problem of unemployment. The rationale behind developing these technical institutes was to improve the matching between the demand of small and medium sized firms which can not afford to hire expensive engineers and which prefer to hire workers with more vocational training. An ex post evaluation of this new education/training strategy is needed.

Promoting longer studies has also costs and risks. The costs are obvious since education is almost free in Tunisia, while the risks depend on the potential transformation of the structure of the economy and of the evolution of the average size and the management culture of Tunisian firms. If the Tunisian economy becomes able to absorb more workers from the highest category of superior education (students holding masters, doctorates or engineering degrees) the strategy could be sustainable. The effectiveness of this strategy depends also on the demographic evolution in the medium run. If there is a slowdown in the pace of increase of labor supply, this strategy could mitigate the unemployment problems in the short run without presenting high risks in the long run.

The second possibility to reduce labor supply is to promote migration of highly educated workers. This option poses some problems. The main problem is that only the best among highly skilled workers are sought by foreign firms. These people usually do not have problems in finding a job in the local market. The second problem is that the national education system, financed by taxpayers produces an elite that is sent to countries where the private returns to education are the highest. The microeconomic impact is positive, while the macroeconomic effects are uncertain. The interactions between labor market policies and migration need certainly to be studied more thoroughly on the basis of empirical data, which are unfortunately scarce.

\section{CONCLUSIONS}

According to our simulation exercise, the current Tunisian employment strategy focused on wage subsidies seems to be in the right direction. It seems at least more effective than investment subsidies (which favor more capital accumulation) or tax reductions for the most intensive sectors in highly 
skilled labor. However, due to the very high pace of growth of highly educated labor supply additional strategies need to be implemented in the short and medium run.

Given the sensitivity of this issue all the options must be considered. Among these, we propose mainly a massive investment in research-development and higher incentives for the promotion of skilled intensive services exports. Thorough ex ante and ex post evaluations of all the options need to be realized to select the most effective measures and avoid the waste of public funds. The prerequisite for ex post evaluations of the different programs of the Tunisian employment strategy is the availability of surveys covering beneficiaries and non beneficiaries of the employment promotion measures.

On the methodological side, the main originality of the model is its efficiency wage setting. Even if wage inequality decreases due to the differentiated evolution of labor supply, the efficiency wage mechanism prevents the decrease of nominal wages of skilled workers. A model with perfect labor markets would have been helpless to address the issue at stake: highly skilled wages would have decreased significantly and everyone would have found a job.

One of the main limits of the model is that it does not allow us to credit issues. The introduction of a financial block in the model would allow the analysis of the effects of a better access to credit on economic activity and employment. 


\section{REFERENCES}

Bchir M.H., Decreux Y., Guerin J.L. and Jean S. (2002), «MIRAGE, a Computable General Equilibrium Model for Trade Policy Analysis », CEPII Working Paper N¹7.

Llop M. and Manresa A. (2004), «The general equilibrium effects of social security contributions under alternative incidence assumptions », Applied Economics Letters, vol 11(13), pp. 847-850.

Marouani M.A. (2009), "Is the end of the MFA a threat?", Review of Development Economics, forthcoming.

Marouani M.A. (2000), « Ouverture commerciale et emploi: un modèle d'équilibre général avec salaires d'efficience appliqué à la Tunisie », Revue Economique, 51(3), pp. 557-69.

Shapiro C. and Stiglitz J.E. (1984), «Equilibrium Unemployment as a Worker Discipline Device. », American Economic Review 74, p. 433-444.

Walsh F. (1999), «A Multisector Model of Efficiency Wages », Journal of Labor Economics 17, p.351-376.

World Bank (2006), «Morocco, Tunisia, Egypt and Jordan after the End of the Multi-Fiber Agreement: Impact, Challenges and Prospects », Report No. 35376, MNA, the World Bank.

World Bank (2004), « Tunisia-Employment Strategy », Report No. 25456, MNSHD, Washington D.C. 